\title{
A PRELIMINARY STUDY FOR EARLY BREAST CANCER DETECTION WITH MICROWAVES
}

\author{
Emine AVŞAR AYDIN
}

\begin{abstract}
Breast cancer is the most common type of cancer in female all over the world. Early detection and treatment gives a chance to overcome this cancer. In breast cancer detection, there are many methods such as X-ray mammography, Magnetic Resonance Imaging, and Ultrasound Imaging. However, existing these methods have limitations such as Xrays, disturbing pressure on the breast, and high cost of devices, etc. Because of all the reasons mentioned, microwave breast imaging has the potential to overcome from some of the limitations of conventional breast cancer screening systems. The physical basis breast cancer detection by microwaves depends on the difference between the dielectric properties of normal and malignant breast tissue. Microwave breast cancer imaging is also a noninvasive method and it has low cost. Therefore, microwave imaging technology for breast cancer detection has attracted much attention by many researchers in these days. By using Computer Simulation Technology Microwave Studio and Antenna Magus Software, breast model with tumor and antennas were generated in this study. The presence of the tumor was investigated using a receiver and a transmitting antenna. While the transmitting antenna was stationary, the receiving antenna was moved to different positions. S11 (return loss) results were evaluated. This study is a preliminary study to determine the location and characteristic features of the tumor. Furthermore, this study will show that scanning methods will determine the location and size of the tumor at higher accuracy and the reconstruction of the reflected waves will allow to clearly determining the location of the tumor.
\end{abstract}

Keywords: antenna design; breast cancer; computer simulation technology (CST); dielectric properties; microwaves

\section{INTRODUCTION}

The breast cancer, which is especially common among women, occurs on the breast tissue covering the wide area between collarbone and armpit and extending on the chest muscles including the chest. Breast cancer emerges from occurrences of mutations and abnormal changes on genes that control the growth and regeneration of cells. Healthy cell, which has the ability of knowing the way and time of division, multiplies uncontrollably by losing this ability due to gene problems and generates cancerous tissues. Unhealthy tissue formation usually occurs at the tip of the breast lobules or milk channels [1].

A study in 2009 has shown that deaths in Turkey are mostly due to cardiovascular disorders and cancer and also women with cancer have the most breast cancer [2, 3]. Again according to the same research, deaths caused by cancer are expected to rise to the first place from 2015. Early diagnosis is important for reduction of cancer-related deaths and treatment. While early stage diagnosis is to help of the cancer treatment, delay of diagnosis reduces chances of treatment [4].

Widespread and primary method used for the screening of breast cancer is X-ray mammography which uses low power X-rays. The breast is compressed for better imaging and exposed to ionizing X-rays even if low-power in X-ray mammography. This method is painful due to compression and there is a possibility of damaging the tissue because it uses ionizing X-rays. [5].

Magnetic resonance imaging (MRI) is an alternative method to X-ray mammography in breast cancer imaging. MRI overcomes the disadvantages of X-ray mammography and can produce successful results about the presence of the tumor in the tissue. But it cannot demonstrate the same success in terms of whether the tumor is good or bad. [5].
Another method used in breast cancer detection is Ultrasound imaging (USI) in which transient waves are used. In USI, imaging is done by collecting back-reflections from the sound waves sent into the tissue. USI consists of disadvantages due to the pressure application with measuring probe and the necessity of using coupling gel to increase the amount of wave penetrating into the tissue by preventing the reflection of sound waves.

Microwave imaging is seen as an alternative method to the above mentioned X-mammography, MRI and USG methods [6-9]. The advantage of microwave imaging is that it allows imaging without the need for any compression or pressure application at lower frequencies than X-rays. With increasing momentum in recent years, microwave imaging located at the center of interest of researchers is still in the research and development phase and prototypes have begun to be created by various research groups $[10,11]$.

In the literature, there are some theoretical and simulation studies. Li et al. [12] presented co-focal microwave imaging algorithm. In the presented study [12], malignant tumor with a diameter of $2 \mathrm{~mm}$ at the bottom of $3.1 \mathrm{~cm}$ deep is placed to developed two-dimensional, anatomically realistic, MRI-derived FDTD (finite difference time Domain, finite differences in time domain) model and developed image creation algorithm is applied. As a result of the application, the tumor is found to be $6 \mathrm{~mm}$ in diameter and $3.3 \mathrm{~cm}$ deep.

The method presented by Xie et al. [13] as multistatic adaptive microwave imaging (MAMI) demonstrates high resolution and low side lobe performance. The characteristics of the method in presented study are shown on a three dimensional breast model simulated by the FDTD method.

Another study in the literature is by Zhou [14]. In microwave imaging studies based on broadband profiles, electric field data scattered from multiple objects in a target 
are collected and a filtered imaging algorithm is applied to these data. Simulation results confirm with measurement results [14].

In this article, the presence of the tumor was investigated using a receiver and a transmitting antenna. While the transmitting antenna was stationary, the receiving antenna was moved to different positions. This study is a preliminary study to determine the location and characteristic features of the tumor.

\section{MATERIAL AND METHOD}

The physical basis for microwave imaging lies in the significant contrast in the dielectric properties between the normal breast tissue and the malignant tissue at microwave frequencies [15]. Microwave imaging (MWI) techniques consist of tomography based and radar based imaging. Communication of through breast is saved by microwave tomography. At the same time, an electrical property map of the region of interest is created using radar-based imaging $[16,17]$. By transmitting electromagnetic waves through the female breast, the scattered field is obtained on the breast in MWI method. While the transmitting antennas are fed by the electromagnetic signals, the receiving antennas collect the electromagnetic signals and define by scattering parameters "S-parameters".

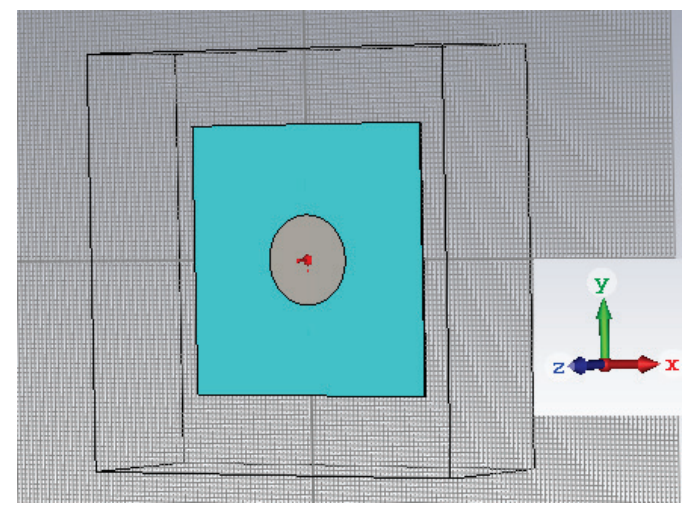

Figure 1 Antenna structure in Antenna Magus Software

Table 1 Features of used antenna

\begin{tabular}{|l|c|}
\hline \multicolumn{1}{|c|}{ Parameter } & Values \\
\hline Dielectric substrate & 2.0 \\
\hline Antenna length & $54.2428 \mathrm{~mm}$ \\
\hline Antenna width & $54.2428 \mathrm{~mm}$ \\
\hline Antenna height & $1 \mathrm{~mm}$ \\
\hline Diameter of patch antenna & $18.08095 \mathrm{~mm}$ \\
\hline Feed-pin radius & $0.25 \mathrm{~mm}$ \\
\hline Coaxial diameter & $1.15128 \mathrm{~mm}$ \\
\hline
\end{tabular}

\subsection{Antenna Model}

A circular pin-fed linearly polarized microstrip patch antenna was preferred in this paper. This antenna was put into Computer Simulation Technology (CST) platform from Antenna Magus Software, a tool for modeling and designing antennas (Fig. 1). The reason for choosing this antenna in this study is its low cost, low profile, lightweight, and high efficiency [17]. Features of the antenna are shown in Tab. 1. On the other hand, microstrip patch antenna with breast model was designed in CST and simulation was performed in CST Design Studio.

\subsection{Breast Model}

As shown in Fig. 2, the breast has hemispherical model and the dimensions of the breast tissues and tumor are shown in Tab. 2. The dielectric properties of each tissue are shown in Tab. 2 [11]. One of the dielectric properties is the conductivity $(\sigma)$, other is the relative permittivity $\left(\varepsilon_{\mathrm{r}}\right)$.

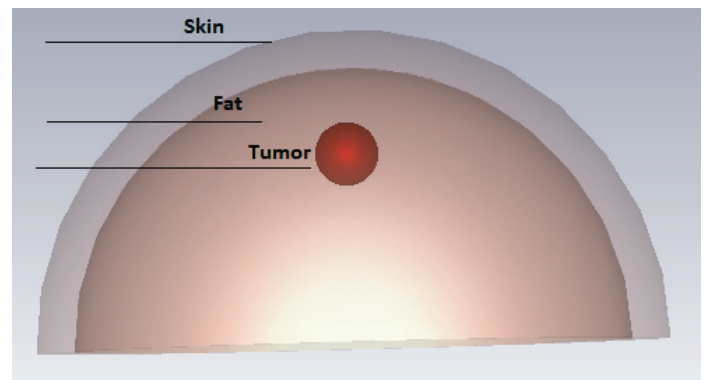

Figure 2 Breast structure in CST Microwave Studio

Table 2 Features of breast structure

\begin{tabular}{|l|c|}
\hline \multicolumn{1}{|c|}{ Tissue Portion } & Size \\
\hline Breast Diameter & $100 \mathrm{~mm}$ \\
\hline Skin Thickness & $2 \mathrm{~mm}$ \\
\hline Tumor Radius & $5 \mathrm{~mm}$ \\
\hline
\end{tabular}

Table 3 Dielectric properties of breast tissues and tumor

\begin{tabular}{|l|c|c|}
\hline \multicolumn{1}{|c|}{ Tissue Portion } & Conductivity $(\mathrm{S} / \mathrm{m})$ & Relative Permittivity \\
\hline Skin & 1.49 & 37.9 \\
\hline Fat & 0.14 & 5.14 \\
\hline Tumor & 1.4 & 50 \\
\hline
\end{tabular}

\section{RESULTS}

In this article, the presence of the tumor was investigated using a receiver and a transmitting antenna. As shown in Figure 3 that while the transmitting antenna was stationary, the receiving antenna was moved to different positions.

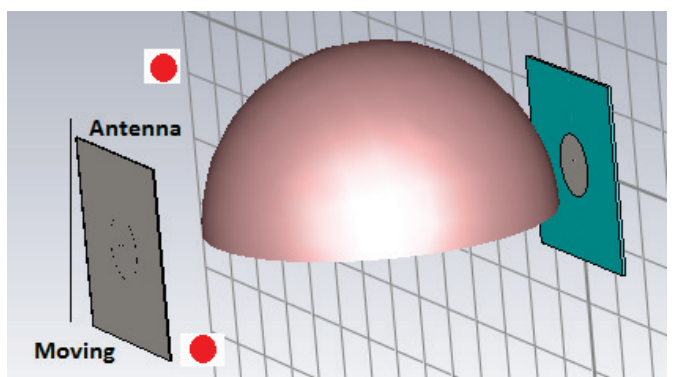

Figure 3 Data collection process using the receiving circular patch antenna moving vertically along two red dots antenna as the transmitting antenna is stationary

As shown in Fig. 3, the receiver antenna was moved up from the bottom of the breast structure to generate scatter signals. S11 (return loss) results were obtained at each antenna position from the bottom of breast structure to top. Graphics ( $a, b, c, d, e$, and f) in Fig. 4 represent different positions of receiving antenna. When the antenna is in the same position as 
the tumor or different position, the results vary. For instance; $b$ graphic shows that the antenna is in the same positon as the tumor and also is different from others. On the other hand, Fig. 5 shows two signals at the same position from two simulation models (one of them is with tumor, other is without tumor). It is clear that two signals' magnitude can be recognized.

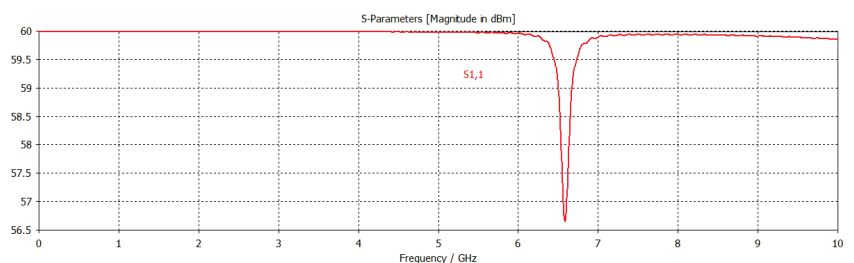

a)

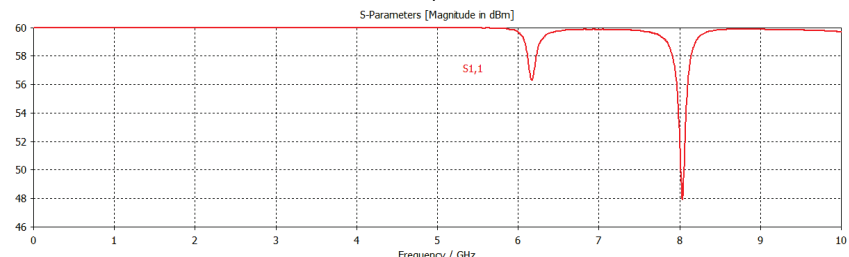

b)

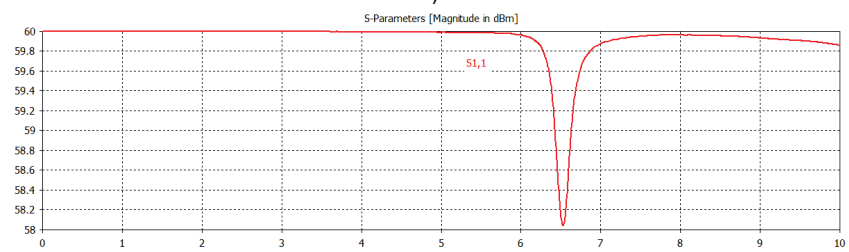

C)

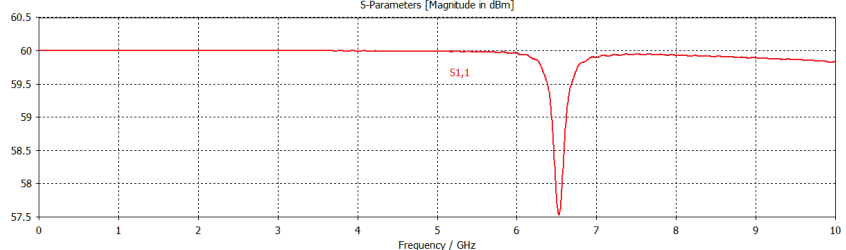

d)

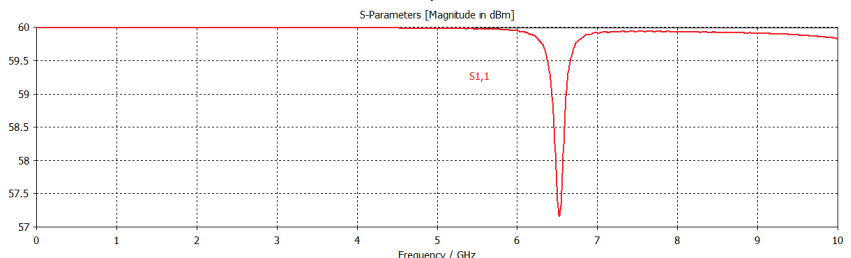

e)

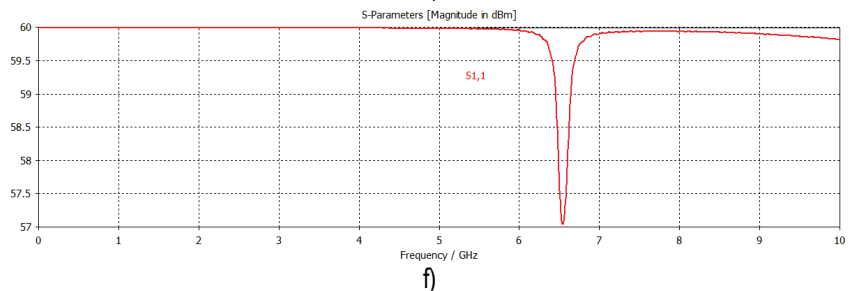

Figure 4 The S11 results (return loss) in frequency domain for each different position

In a study, the S11 simulations with and without tumors were compared at some antenna positions [18]. The positions where the antenna is on the axis of a tumor, S11 of the two simulations with tumor and without tumor were differentiated, in the same sub-band of 6 to $8 \mathrm{GHz}$, (Fig. 6).

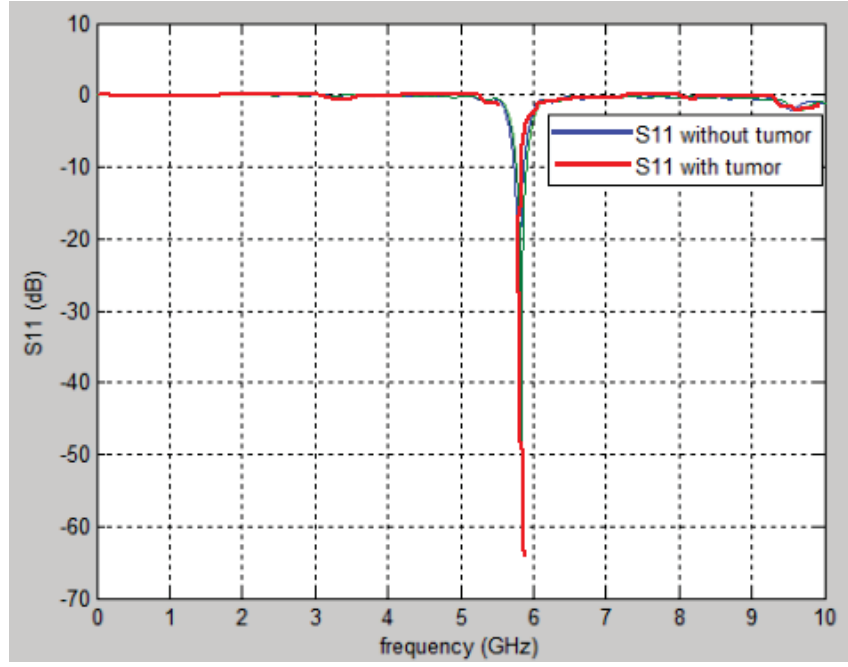

Figure 5 The magnitude of two signals (with tumor and without tumor)

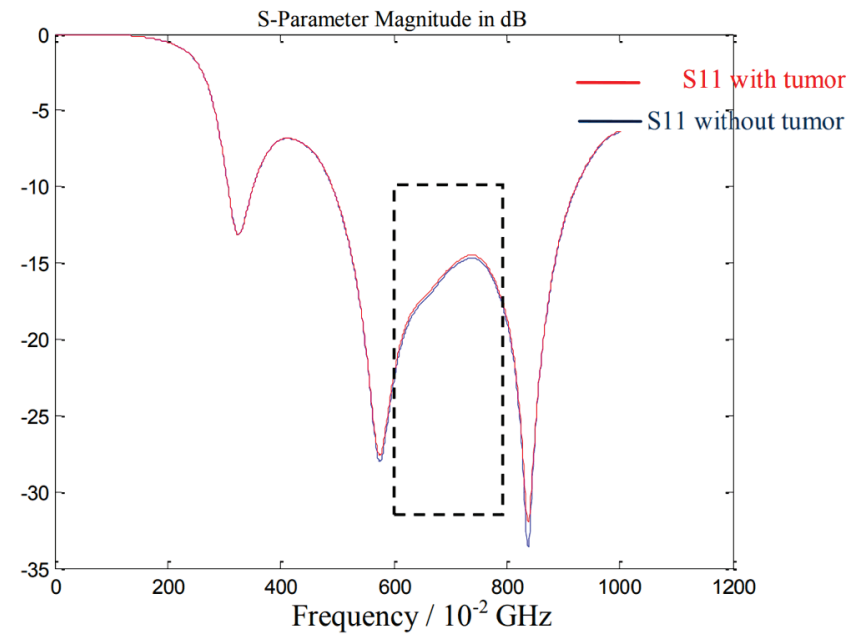

Figure 6 Comparison of two S11 (with and without tumors) the antenna is placed away from the axis the tumor [18]

\section{CONCLUSION}

In this study, a microwave imaging system was preferred to detect breast cancer. CST software was used to create a lifelike breast phantoms and a circular pin-fed linearly polarized microstrip patch antenna which generates a microwave signal. The receiver antenna was moved up from the bottom of the breast structure to generate scatter signals. This movement repeated for breast model with tumor and without tumor. The difference between tumor and without tumor showed that microwave imaging system is successful for breast cancer detection. In future work, a viable $3 \mathrm{D}$ image reconstruction process will be applied and will be repeated experimentally at the same time. This study will show that scanning methods will determine the location and size of the tumor at higher accuracy and the reconstruction of the reflected waves will allow to clearly determining the location of the tumor.

\section{REFERENCES}

[1] Meme Kanseri, Wikipedia, http://tr.wikipedia.org/wiki/Meme kanseri, Feb. 2014. 
[2] Kanser Kayıtçılı̆̆ı, Türkiye Halk Sağlığı Kurumu Kanser Daire Başkanlığı, http://www.kanser.gov.tr/daire-faaliyetleri/ kanser-kayitciligi/108-t\%C3\%BCrkiyede-kanser-kayitcigi. html\#sthash.rW1OWN14.dpuf, Dec. 2013.

[3] Gültekin, M. (2013). Kanser Dairesi Faaliyetleri.

[4] Kanser Türleri: Meme Kanseri, Türkiye Halk Sağlığı Kurumu Kanser Daire Başkanlığı, http://www.kanser.gov.tr/kanser/ kanser-turleri/49-memekanseri.html\#sthash.RFWV7MIA. dpuf (2013).

[5] Hassan, A. M. \& El-Shenawee, M. (2011). Review of electromagnetic techniques for breast cancer detection. IEEE Reviews in Biomedical Engineering, 4, 103-118. https://doi.org/10.1109/RBME.2011.2169780

[6] Xu, M., Thulasiraman, P., \& Noghanian, S., (2011). Microwave Tomography for Breast Cancer Detection on Cell Broadband Engine Processors. J. Parallel Distrib. Comput., 72, 1106-1116. https://doi.org/10.1016/j.jpdc.2011.10.013

[7] Santorelli, A. \& Popovic, M. (2011). SAR Distribution in Microwave Breast Screening: Results with TWTLTLA Wideband Antenna. Intelligent Sensors, Sensor Networks and Information Processing (ISSNIP) / Adelaide, 11-16. https://doi.org/10.1109/ISSNIP.2011.6146531

[8] Lazaro, A., Girbau, D., \& Villarino, R. (2010). Simulated and Experimental Wavelet-based Detection of Breast Tumor using a UWB Radar. $40^{\text {th }}$ European Microwave Conference / Paris, 373-376.

[9] Zhang, D. \& Mase, A. (2011). Ultrashort-Pulse Radar System for Breast Cancer Detection Experiment: Imaging in Frequency Band. Microwave Conference Proceedings (CJMW) / Hangzhou, 1-3.

[10] Meaney, P. M., Fanning, M. W., Li, D., Poplack, S. P., \& Paulsen K. D. (2000). A Clinical Prototype for Active Microwave Imaging of the Breast. IEEE Transactions on Microwave Theory and Techniques, 48(11), 1841-1853. https://doi.org/10.1109/22.883861

[11] Klemm, M., Craddock, I. J., Leendertz, J. A., Preece, A., Gibbins, D. R., Shere, M., \& Benjamin, R. (2010). Clinical Trials of a UWB Imaging Radar for Breast Cancer. Antennas and Propagation (EuCAP), 2010 Proceedings of the Fourth European Conference on.

[12] Li, X. \& Hagness S. C. (2001). A Confocal Microwave Imaging Algorithm for Breast Cancer Detection. IEEE Microwave and Wireless Components Letters, 11(3), 130-132. https://doi.org/10.1109/7260.915627

[13] Xie, Y., Guo, B., Xu, L., Li, J., \& Stoica, P. (2006). Multistatic Adaptive Microwave Imaging for Early Breast Cancer Detection. IEEE Transactions on Biomedical Engineering, 53(8), 1647-1657. https://doi.org/10.1109/TBME.2006.878058

[14] Zhou, Y. (2010). Microwave Imaging based on Wideband Range Profiles. Progress in Electromagnetics Research Letters, 19, 57-65. https://doi.org/10.2528/PIERL10100608

[15] Xie, Y., Guo, B., Xu, L., Li, J., \& Stoica, P. (2006). Multistatic adaptive microwave imaging for early breast cancer detection. IEEE Trans. Biomed. Eng., 53(8), 16471657. https://doi.org/10.1109/TBME.2006.878058

[16] Bahramiabarghouei, H., Porter, E., Santorelli, A., Gosselin, B., Popovi, M., \& Rusch, L. A. (2015). Flexible 16 antenna array for microwave breast cancer detection. IEEE Trans. Biomed. Eng., 62(10), 2516-2525. https://doi.org/10.1109/TBME.2015.2434956

[17] Eltigani, F. M., Yahya, M. A. A., \& Osman, M. E. (2017). Microwave Imaging System for Early Detection of Breast Cancer. 2017 International Conference on Communication, Control, Computing and Electronics Engineering (ICCCCEE)
/ Khartoum, Sudan. https://doi.org/10.1109//CCCCEE.2017.7866083

[18] Chouiti, S. M., Merad, L., \& Meriah, S. M. A Microwave Imaging Technique Implementation for Early Detection of Breast Tumors. Advances in Circuits, Systems, Signal Processing and Telecommunications, pp. 233-236.

\author{
Author's contact: \\ Emine AVŞAR AYDIN \\ Adana Science and Technology University, \\ Department of Aeronautical Engineering \\ Adana Bilim ve Teknoloji Üniversitesi, \\ Gültepe Mh., Sarıçam/Adana, Turkey \\ eaydin@adanabtu.edu.tr \\ rasvaenime@gmail.com
}

